\title{
EFFECT OF ACCELERATED MOISTURE DAMAGE ON CREEP COMPLIANCE CHARACTERISTICS OF ASPHALT CONCRETE MIXTURES
}

\author{
Ayman M. Othman \\ Civil Engineering Department, Aswan Faculty of Engineering, South Valley \\ University, Aswan, Egypt \\ Hassan Y. Ahmed \\ Civil Engineering Department, Faculty of Engineering, Assiut University, Assiut, \\ Egypt
}

(Received January 15, 2006 Accepted February 7, 2006)

\begin{abstract}
Major pavement deterioration can be attributed to the presence of water on the pavement surface. Within this framework, this research is focused on studying the impact of accelerated moisture conditioning on pavement deterioration. This study is based on laboratory evaluation of creep characteristics and mechanical properties of asphalt concrete mixtures. This evaluation can aid in assessing the longterm stripping susceptibility and permanent deformation potential of asphalt concrete mixtures. Cement dust was incorporated in the mixture as mineral filler and compared with traditional lime stone filler. Accelerated moisture damage program was established to evaluate the mixture resistance to moisture damage. Marshall specimens were immersed in a water bath under vacuum of $510 \mathrm{~mm}$ of mercury $(\mathrm{Hg})$ for different moisture conditioning periods of 0, 1, 2 and 7 days. A power law model was used to characterize the creep compliance behavior of the studied mixtures. Creep testing results have revealed that the creep compliance power law parameters have a strong relationship with mixture type and moisture conditioning period. The creep resistance of the studied mixtures, as indicated by the creep compliance parameters, decreases as the moisture conditioning period increases. Results also revealed an enhancement in the creep resistance, Marshall stability, indirect tensile strength and compressive strength for mixtures containing cement dust as compared to mixtures with traditional lime stone filler.
\end{abstract}

KEYWORDS: Cement dust; Asphalt Concrete Mixtures; Moisture Damage; Creep Compliance; Marshall stability ; Indirect Tensile Strength; Compressive Strength.

\section{INTODUCTION}

Recently, a major source of pavement deterioration is observed due to the presence of water on the pavement surface. In general moisture is considered a serious enemy to the long life performance of all pavements since it causes stripping or loss of the bond between the asphalt binder and the aggregate. Therefore, designers and construction engineers need to take into account proper solutions to minimize this form 
of pavement damage. The potential of moisture damage can be controlled through using anti-stripping additives in asphalt mixtures. Many research activities were conducted to identify the possible causes of stripping, methods for predicting stripping potential of asphalt paving mixtures, and use of additives to minimize or prevent stripping.

The stripping phenomenon was intensively studied by many researchers. Cheng et al [1] stated that, the stresses that cause failure of the asphalt film include water pressure and erosion caused by traffic and thermal cycles. Excessive pore pressure buildup from stresses induced by traffic has also been reported as the cause of stripping in asphaltic mixtures [2]. Void water pressure can be developed up to $20 \mathrm{psi}$ under differential thermal expansion of the compacted asphalt mixture and could exceed the adhesive strength at the binder-aggregate surface. Numerous test methods have been developed to predict moisture damage on asphalt mixtures [3, 4]. These test methods attempted to simulate the moisture damage that would occur in the field. Most of these tests use tensile strength ratios (TSR) to measure the stripping potential of various hot mix asphalt (HMA) mixtures. After evaluating different testing procedures Khosla [5] stated that, the TSR value could be used as a valid indicator of stripping performance. Similar conclusion was also reported by Kim et al. [6] who conducted moisture sensitivity tests on field prepared mixtures using resilient modulus and indirect tensile strength.

Various anti-stripping additives have been developed to control the stripping problem [7]. The main function of anti-stripping additives is to promote adhesion between asphalt and aggregate that can resist the water action. Most anti-stripping agents reduce surface tension between the asphalt and aggregate in a mixture. When surface tension is reduced, increased adhesion of the asphalt to the aggregate is promoted [8]. The most common anti-stripping agents include lime and liquid additives. Lime additives are considered an accepted method of minimizing moisture susceptibility of asphaltic mixtures since they tend to increase the tensile strength of HMA mixtures [9]. Liquid antistrips that are mainly amine-based compounds are designed to give the asphalt binder an electrical charge opposite that of the aggregate and hence promote better adhesion at the asphalt/aggregate interface [10,11].

Nowadays, environmental problems were incorporated due the successive increase of the generated waste by product materials. An important example of such material is cement dust that is formed in large quantities by Portland cement factories. Due to its very fine nature it causes air pollution which affects negatively on the environment and causes serious problems to humans health, animals and plants. Therefore, the use of such waste as non-conventional raw material in highway construction can have beneficial economical and environmental impact. Using of Cement dust as a mineral filler in highway asphalt concrete has been reported by many researchers. A recent study made by Taha [12] indicated through Marshall testing that cement dust can be used as a substitution for lime stone mineral filler in asphalt paving mixtures. It was also shown that the components of cement dust can assist in promoting stripping resistance and thus can replace hydrated lime or liquid antistripping agents $[13,14]$.

Within this research, cement dust is proposed as an anti-stripping agent for asphalt concrete mixtures. Cement dust was incorporated in the mixture as a mineral 
filler and compared with traditional lime stone mineral filler. Accelerated moisture damage program was established to evaluate the long-term stripping susceptibility of the studied two mixtures. Marshall specimens were immersed under vacuum in a water bath at different conditioning periods of 1,2 and 7 days. Creep compliance characteristics of the conditioned mixtures were evaluated based on static creep test to study the viscoelastic behavior of the studied mixtures and to predict their potential to permanent deformation. Creep test results were compared with the results of traditional mechanical testing as Marshall stability, indirect tensile strength and unconfined compressive strength.

\section{CREEP COMPLIANCE CHARACTERISTICS}

Permanent deformation and rutting are among the major load-associated distress types affecting the performance of asphalt concrete pavements. The static creep test has been widely used [15] to assess the rutting or permanent deformation potential of asphaltic mixtures. Since creep is a time-dependent function, it can provide extremely important practical information about long term performance of asphaltic mixtures. The static creep test is normally conducted by applying a static load to an asphalt concrete specimen and measure the resulting deformation with time. In creep testing, several unique moduli can be defined to describe the material behavior. In particular, the "creep" or time dependent modulus can be defined as the ratio between applied creep stress to resulting creep strain at any time $\left(\mathrm{E}(\mathrm{t})=\sigma_{0 /} \varepsilon_{(\mathrm{t})}\right)$. The "modulus" of a material is a very important property that relates stress to strain. However, for viscoelastic materials, it is more advantageous to use the term "compliance" or $\mathrm{D}(\mathrm{t})$. Compliance is the reciprocal of the modulus and is expressed as;

$$
\mathrm{D}(\mathrm{t})=\varepsilon_{(\mathrm{t})} / \sigma_{0}
$$

Where $\varepsilon_{(\mathrm{t})}$ is the creep strain at time (t) and $\sigma_{0}$ is the applied creep stress. A typical creep compliance - stress - time behavior of a material under static creep test is shown in Figure 1.

The creep compliance $\mathrm{D}(\mathrm{t})$, as measured by the static creep test can be divided into two components. The first component is $\mathrm{D}_{0}$, which represents the instantaneous compliance at the beginning of the test. The second component is the viscoelastic compliance component $\left(\mathrm{D}_{\mathrm{ve}}(\mathrm{t})\right)$ at any time during the test. The viscoelastic compliance component can be represented by a power law model [15]. Based on this model the viscoelastic compliance component at any time within the stable loading stage and before failure occurs, can be expressed as;

$$
D_{\text {ve }}(t)=D(t)-D_{0}=a t^{m}
$$

Where;

$D_{\text {ve }}(t)=$ Viscoelastic compliance component at time ( $\left.t\right)$

$\mathrm{D}(\mathrm{t}) \quad=$ Total creep compliance at time $(\mathrm{t})$

$\mathrm{D}_{0} \quad=$ Instantaneous compliance

$\mathrm{t}=$ Loading time

$\mathrm{a}, \mathrm{m}=$ Material regression coefficients 


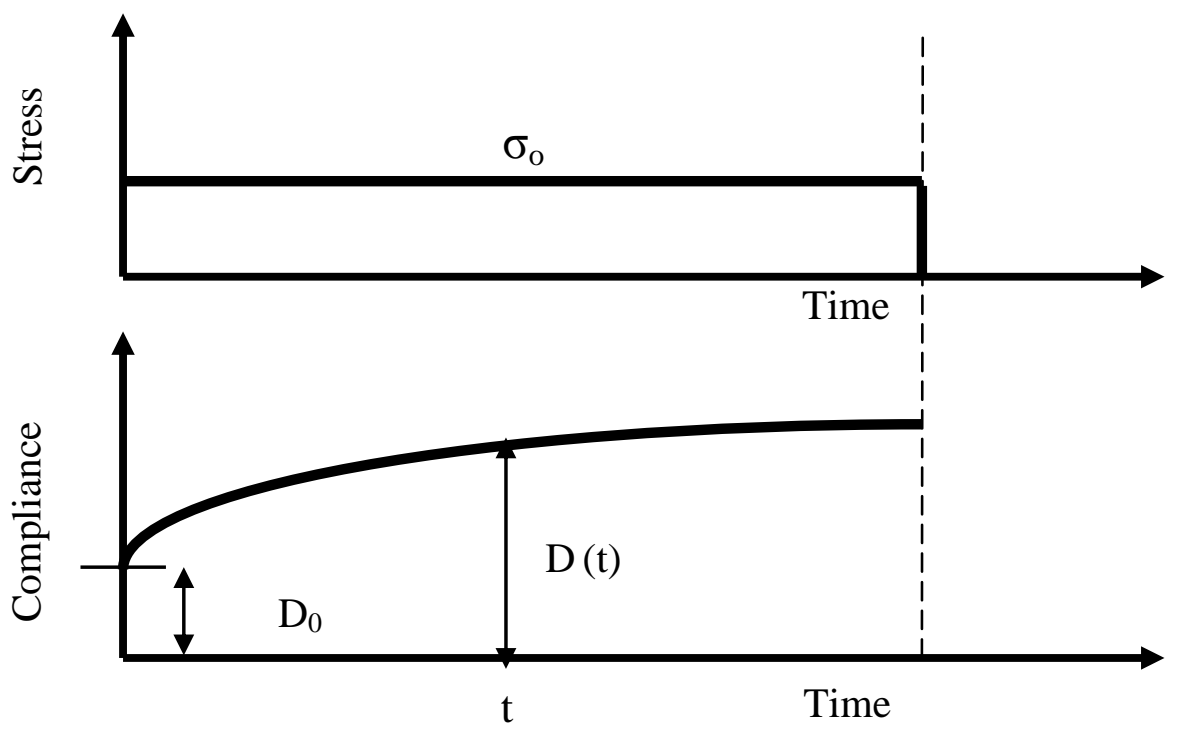

Figure 1: Typical Creep Compliance - Stress- Time Relationship.

In the above model, the regression coefficients "a" and " $\mathrm{m}$ " are generally referred to as the creep compliance parameters. These parameters are the general indicators of the permanent deformation behavior of the materials. In general, the larger the value of "a", the larger the $\mathrm{D}_{\text {ve }}(\mathrm{t})$ value, and hence the larger the potential of the material for permanent deformation. In addition, for a constant "a" value, as the slope parameter " $m$ " increases, the $D_{\text {ve }}(t)$ value increases as well and the potential for permanent deformation becomes larger. The creep compliance parameters $(\mathrm{a}, \mathrm{m})$ are used within this research for characterizing the asphaltic mixtures creep resistance and to assess their potential to rutting or permanent deformation.

\section{MATERIAL CHARACTERIZATION}

Asphalt binder 60/70 was used within this research. Coarse aggregate and fine aggregate (Bulk specific gravity of 2.77 and 2.68, respectively) were used in the preparation of the asphalt concrete mixtures. The selected gradation of aggregate incorporated in all asphalt concrete specimens confirms to the mid point of the standard 4-c aggregate gradation specified in the Egyptian highway standard specifications. White cement dust was incorporated in the mixture as mineral filler and compared with traditional lime stone filler. Cement dust is a waste material that is generated as a by-product of the manufacture of Portland white cement. It is generated during the calcining process in the kiln. Table 1 shows the compositions of cement dust. in Table 2.

Mechanical properties of cement dust and lime stone mineral filler are shown 
Table 1: Components of Cement Dust.

\begin{tabular}{|c|c|}
\hline Component & Percentage \\
\hline $\mathrm{Al}_{2} \mathrm{O}_{3}$ & 5.5 \\
\hline $\mathrm{SiO}_{2}$ & 20.5 \\
\hline $\mathrm{Fe}_{2} \mathrm{O}_{3}$ & 1.5 \\
\hline $\mathrm{CaO}$ & 62.5 \\
\hline $\mathrm{MgO}$ & 2 \\
\hline $\mathrm{SO}_{3}$ & 8 \\
\hline
\end{tabular}

Table 2: Mechanical Properties of Used Mineral Filler Materials.

\begin{tabular}{|l|c||c|}
\hline \multicolumn{1}{|c|}{ Properties } & Cement Dust & Lime Stone \\
\hline \hline \% Passing sieve No. 30 & 100 & 100 \\
\hline \% Passing sieve No. 50 & 100 & 95 \\
\hline \% Passing sieve No. 200 & 85 & 78 \\
\hline Plasticity Index & 2 & 3 \\
\hline Specific Gravity & 2.8 & 2.55 \\
\hline
\end{tabular}

\section{LABORATORY TESTING PROGRAM}

\subsection{Sample Preparation}

Two different mixtures with two different mineral filler types were prepared within this study. The two selected mineral fillers types include cement dust and lime stone. Mineral fillers were blended with the natural aggregate to obtain a uniform natural aggregate mix before mixing with the asphalt binder. All examined asphalt concrete mixtures were prepared in accordance with the Standard 75-blow Marshall design method for designing hot asphalt concrete mixtures, designated as (ASTM Designation: D 1559-89) using automatic compaction. Constant bitumen content of 5\% was used. Marshall specimens ( 2.5 inches thick and 4 inches diameter) were produced for each mixture. To provide adequate data three samples were prepared from each mixture for each test.

\subsection{Moisture Damage Program}

Accelerated moisture damage program was established on the studied mixtures to smiluate the effect of moistre damage on the roads. Marshall specimens (72 samples) from the two studied mixtures were vacuum saturated in water at a vacuum of $510 \mathrm{~mm}$ of mercury $(\mathrm{Hg})$ at different conditioning periods of 1,2 and 7 days at a controlled temperature of $\left(25 \pm 1.0{ }^{\circ} \mathrm{C}\right)$. Creep, Marshall stability, indirect tensile strength and unconfined compressive strengths tests were performed on moisture conditioned samples. The results were compared with those for unconditioned (control) samples. 


\subsection{Creep Test}

Creep tests were performed on the moisture conditioned Marshall specimens using a standard consolidation-testing machine. The cylindrical specimens were loaded in the axial direction at a pressure of $613 \mathrm{kPa}$ for 60 minutes and before failure occurs. The static creep test was performed at room temperature that ranged between $27-30^{\circ} \mathrm{C}$. Strain was recorded during the test at 1, 2, 3, 4, 5, 10, 15, 20, 25, 30, 35, 40, 45, 50, 55 and 60 minutes so that a creep plot (compliance vs. time) could be obtained.

\subsection{Mechanical Testing Procedure}

Mechanical testing program was conducted to evaluate the effect of moisture conditioning on the mechanical behavior of the two studied mixtures. The testing program include running Marshall stability, indirect tensile strength and unconfined compressive strength tests. The results can be used to assess the long-term stripping susceptibility of the bituminous mixtures. The Marshall stability test was conducted according to ASTM Designation (D 1559-82), while the indirect tensile tests was conducted in accordance with (ASTM D4123). The unconfined compression tests were performed using a 15-ton capacity universal testing machine. Marshall specimens were placed on the lower fixed platen of the testing machine. Load was applied with a uniform rate of $2 \mathrm{~mm} / \mathrm{min}$ on the circular face of the testing samples until failure occurred. The maximum load to failure was recorded and hence the compressive strength was calculated.

\section{RESULTS AND DISCUSSION}

\subsection{Creep Test Results}

The creep compliance was calculated from the applied creep stress and the measured strain over time based on Equation (1). Relationships between the creep compliance and time for each of the lime and cement dust specimens at different moisture conditioning period are shown in Figures $(2,3)$, respectively. It could be noted from those figures that, for both lime and cement dust mixtures, the dry specimen has displayed the lowest instantaneous (initial) compliance and the lowest total compliance during the entire test. As the period of moisture conditioning increases both the initial and total compliance increase as well. Maximum initial and total compliance was observed for specimen that was subjected to 7 days moisture conditioning period. A comparison between the creep compliance behavior of lime and cement dust mixtures show that, mixtures with cement dust exhibit lower initial and lower total compliance at the same period of moisture conditioning.

The creep compliance regression coefficients "a" and " $\mathrm{m}$ " can be obtained by applying the power law model given in Equation 2 on the creep compliance measurement shown in Figures $(2,3)$. Table 3 presents the regression coefficients "a" and $" \mathrm{~m}$ " for the lime stone and cement dust mixtures at different moisture conditioning periods. The values of "a" and " $\mathrm{m}$ " given in Table 3 are obtained considering the compliance values in $\mathrm{mm}^{2} / \mathrm{N}$ and time values are in minutes. 


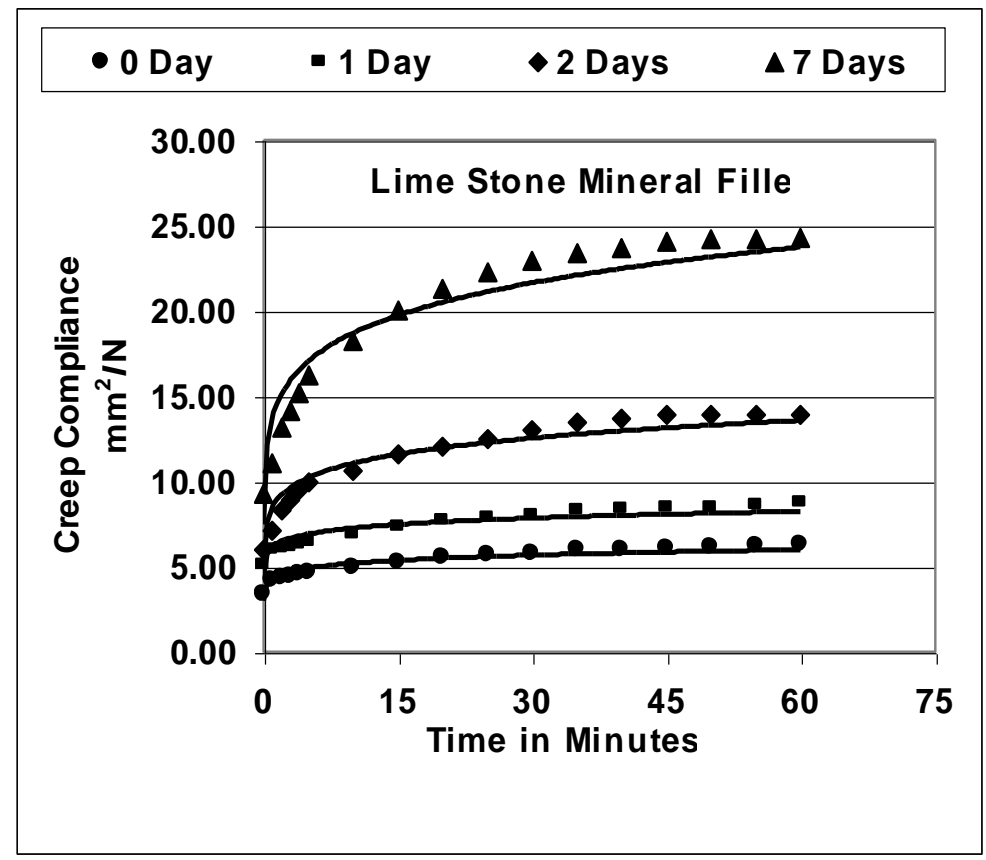

Figure 2: Creep Compliance Vs. Time at Different Conditioning Periods for Asphalt Mixture Containing Lime Stone Mineral Filler.

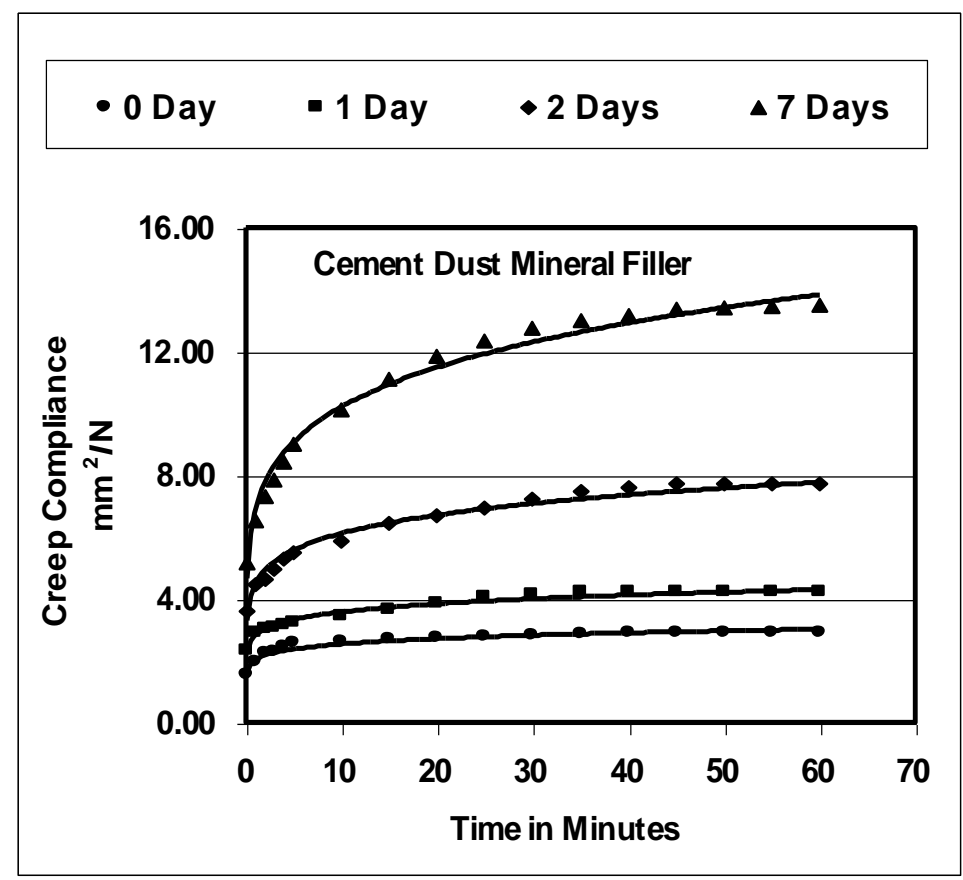

Figure 3: Creep Compliance Vs. Time at Different Conditioning Periods for Asphalt Mixture Containing Cement Dust Mineral Filler. 
Table 3: Creep Compliance Coefficients For Lime and Cement Dust Mixtures at Different Moisture Conditioning Periods.

\begin{tabular}{|c|c|c|c|c|}
\hline \multirow{2}{*}{$\begin{array}{c}\text { Moisture } \\
\text { Conditioning } \\
\text { Period (Day) }\end{array}$} & \multicolumn{2}{|c|}{ "a" } & \multicolumn{2}{c|}{ "m" } \\
\cline { 2 - 5 } & Stone & $\begin{array}{c}\text { Cement } \\
\text { Dust }\end{array}$ & $\begin{array}{c}\text { Lime } \\
\text { Stone }\end{array}$ & $\begin{array}{c}\text { Cement } \\
\text { Dust }\end{array}$ \\
\hline 0 & 0.44 & 0.32 & 0.47 & 0.42 \\
\hline 1 & 0.57 & 0.38 & 0.55 & 0.45 \\
\hline 2 & 0.97 & 0.68 & 0.61 & 0.49 \\
\hline 7 & 1.77 & 1.28 & 0.78 & 0.53 \\
\hline
\end{tabular}

(Note: $a, m$ values are obtained considering compliance in $\mathrm{mm}^{2} / \mathrm{N}$ and time in minutes)

As mentioned earlier, the coefficients "a" and " $\mathrm{m}$ " are indicators of the permanent deformation behavior of asphaltic mixtures. The larger the value of "a" and " $\mathrm{m}$ " the larger the mixture compliance and the larger is the potential to permanent deformation. Relationship between coefficient (a) and moisture conditioning period for the lime stone and cement dust mixtures is shown in Figure 4. It can be seen that, for lime stone mixture, the value of (a) increases with a uniform rate at moisture conditioning period from 0 to 2 days, then it rapidly increases for higher conditioning periods. This indicates an uncontrolled moisture damage effect associated with a rapid drop in the creep resistance and a rapid increase in its potential to permanent deformation. For cement dust mixture, the coefficient (a) increases with a uniform rate as the moisture conditioning period increases which indicates a controlled moisture damage effect.

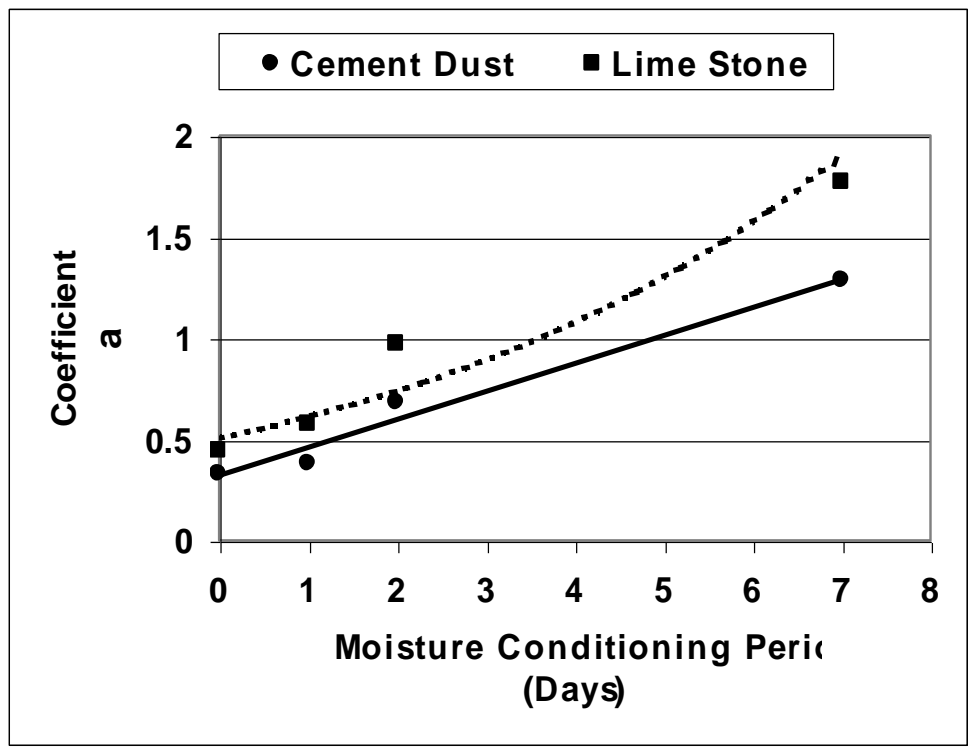

Figure 4: Variation of Compliance Coefficient (a) with the Change in Moisture Conditioning Period. 
Figure 5 presents the relationship between the creep compliance coefficient (m) and moisture conditioning period for the lime stone and cement dust mixtures. The figure indicates that, the parameter $(\mathrm{m})$ almost increases with the same trend as parameter (a) for both mixtures. It is also indicated from Figures $(4,5)$ that, the cement dust mixture always exhibits lower (a) and (m) as compared to mixture with lime stone filler at the same moisture conditioning period. Hence, cement dust mixture is considered more superior in resisting permanent deformation in both dry and wet conditions. This enhancement can be related to the modification of the surface chemistry at the aggregate-asphalt interface to promote better adhesion. This enables cement dust to act like a bridge between aggregates and the asphalt binder that keeps the water from seeping between them and prevents it from dislodging the bonded asphalt. This promotes to the mixture the ability to resist the water act and hence decelerate the effect of moisture damage.

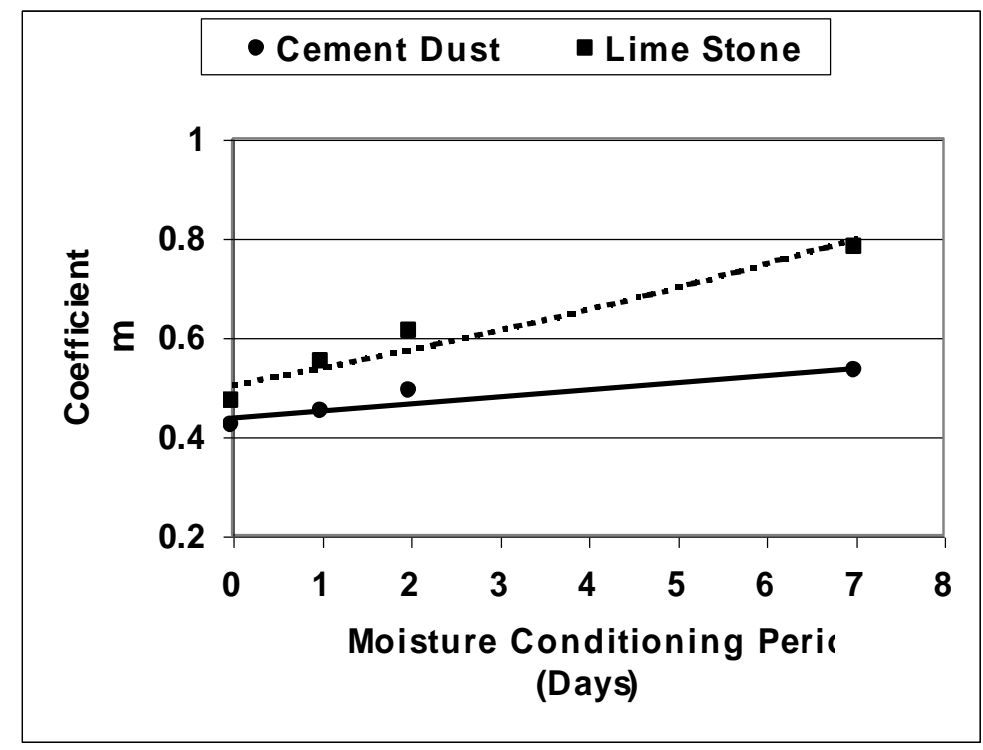

Figure 5: Variation of Compliance Coefficient $(\mathrm{m})$ with the Change in Moisture Conditioning Period.

\subsection{Mechanical Properties Results}

Relationships between Marshall stability, indirect tensile and unconfined compressive strength values and moisture conditioning period for the two studied mixtures are presented in Figures $(6,7, \mathbf{8})$. It is evident that, the values of Marshall stability, indirect tensile and unconfined compressive strength decrease for both mixtures as the moisture conditioning period increases. This reflects the damage introduced to the mixtures due to the act of moisture. It is also noticed that the at the same moisture conditioning period, the cement dust mixture exhibits higher values of Marshall stability, indirect tensile and unconfined compressive strength as compared to 
the lime mixture. This indicates that adding cement dust as mineral filler for asphalt concrete mixtures can produce mixtures that are more superior in resisting the effect of moisture damage. These findings agree with the creep results shown previously.

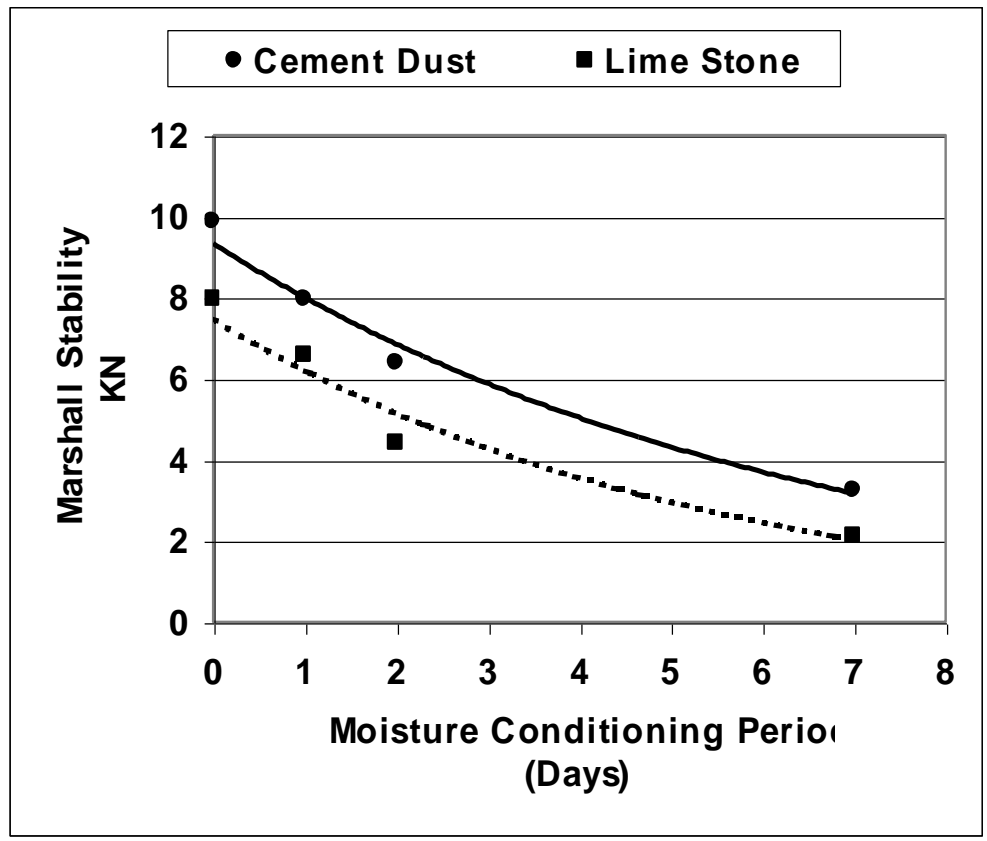

Figure 6: Effect of Moisture Conditioning Period on Marshal Stability.

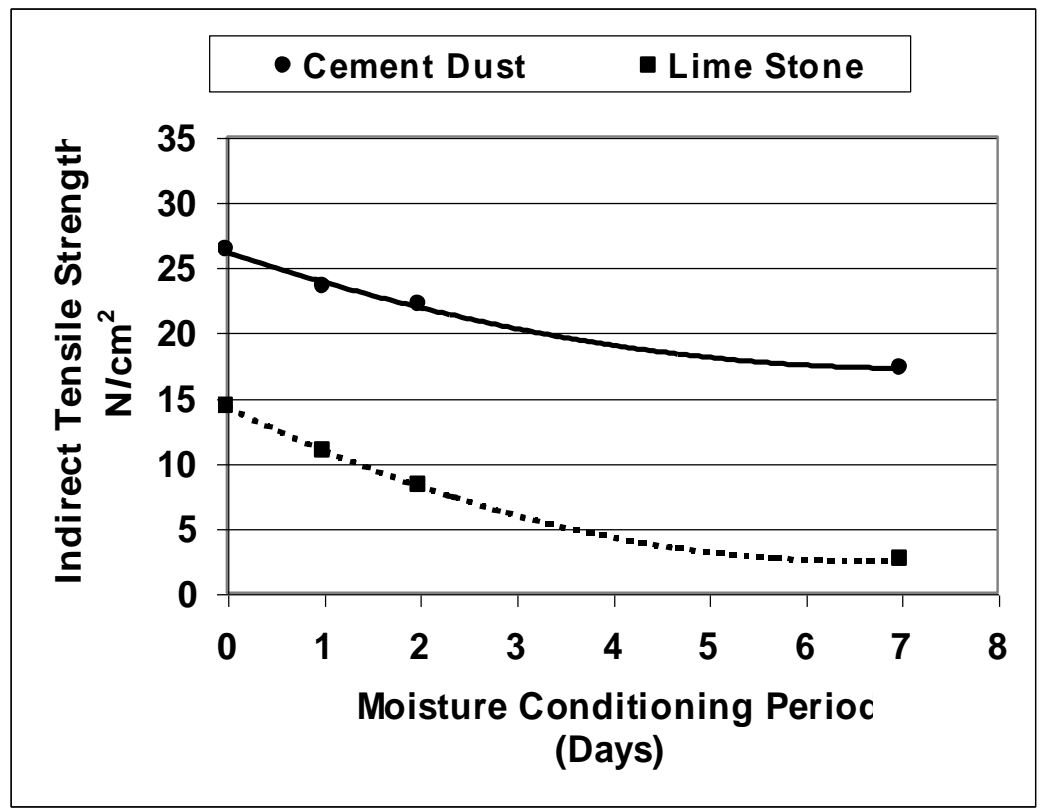

Figure 7: Effect of Moisture Conditioning Period on Indirect Tensile Strength. 


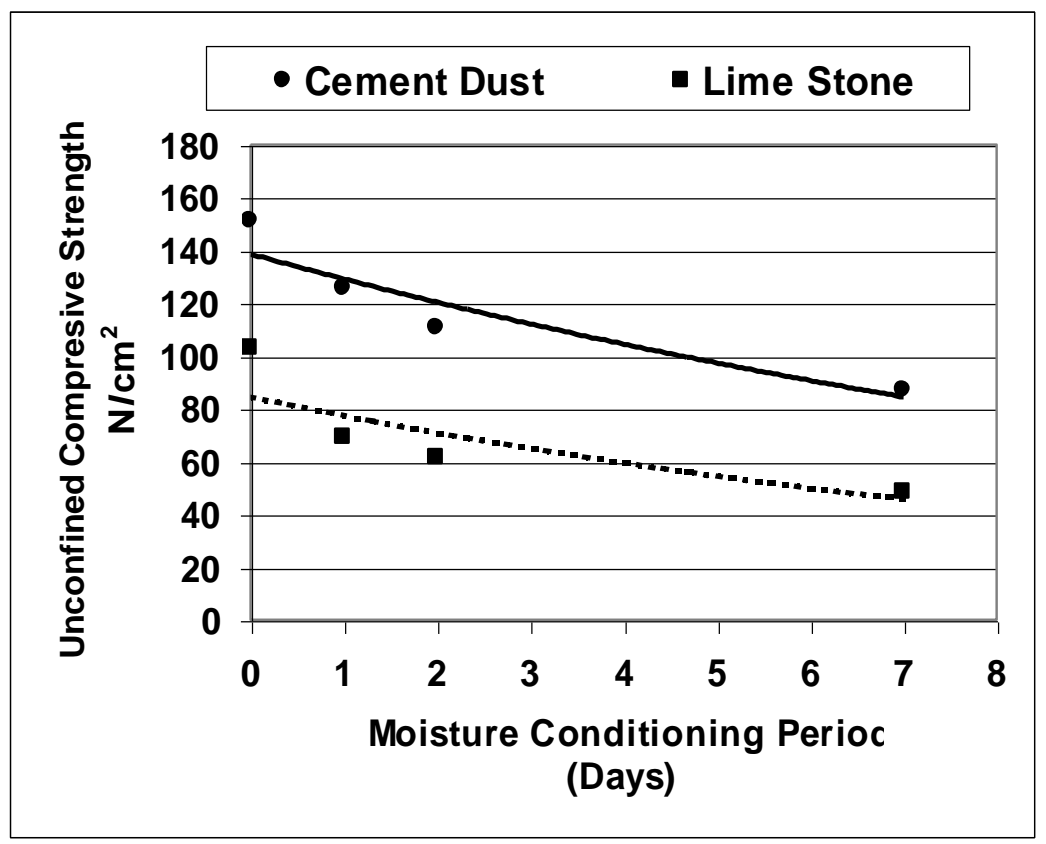

Figure 8: Effect of Moisture Conditioning Period on Compressive Strength.

\section{CONCLUSION}

A power law model has been successfully used to characterize the creep compliance behavior of asphaltic mixtures. Mixtures include white cement dust as a mineral filler was studied and compared with mixtures containing traditional lime stone mineral filler. The current study reveals that, creep compliance parameters $(\mathrm{a}, \mathrm{m})$ have a strong relationship with mixture type and moisture conditioning period. The creep resistance of the two studied mixtures, as indicated by the parameters $(\mathrm{a}, \mathrm{m})$, decreases as the moisture conditioning period increases. Mixtures with cement dust mineral filler experienced higher creep resistance when compared to traditional lime stone mixtures over the entire range of moisture conditioning periods. Mechanical testing results as indicated by Marshall stiffness, indirect tensile and unconfined compressive strength were found to be consistent with creep testing results. Thus it can be concluded that, the creep compliance parameters have been successfully used to characterize the potential of asphalt concrete mixtures to permanent deformation. It is also concluded that cement dust can be successfully used to decelerate the effect of moisture damage in asphalt concrete mixtures. This in addition to the environmental benefits that can be gained when using cement dust in asphalt paving technology.

\section{REFERENCES}

[1] D. Cheng, D. N. Little, R. L. Lytton and J. Holste, "Use of Surface Free Energy of Asphalt-Aggregate System to Predict Moisture Damage Potential", Journal of the Association of Asphalt Paving Technologists, 2002, Vol. 71, Pp. 59-88. 
[2] Thomas, Ken, Huang, Shin-Che; and Mckay John; "Impact of Asphalt Aging on Moisture Susceptibility" WRI, 2003.

[3] Mccann M., Sebaaly P., "Resilient Modulus, Tensile Strength, and Simple Shear Test to Evaluate Moisture Sensitivity and the Performance of Lime in Hot Mix Asphalt Mixtures", TRB 2003, Annual Meeting. Paper 442.

[4] Eduardo Castada Pinzn and Christian Such, "Evaluation The Moisture Sensitivity of Bituminous Mixtures Using Complex Modulus Approach", Presented at the 83rd Transportation Research Board Annual Meeting, Washington, D.C, January 11-15, 2004.

[5] Khosla, N. P., B. G. Birdsall, and S. Kawaguchi, "Evaluation of Moisture Susceptibility of Asphalt Mixtures: Conventional and New Methods." Transportation Research Record 1728. Washington D.C., National Academy Press, 2000.

[6] Kim, Little and Lytton, "Effect Of Moisture Damage On Material Properties and Fatigue Resistance of Asphalt Mixtures", Presented at the 83rd Transportation Research Board Annual Meeting, Washington, Dc, January 11-15, 2004.

[7] Cross S. A., and Voth M. D., "Evaluation of Anti-Stripping Agents Using the Asphalt Pavement Analyzer, K-TRAN Report No. KU-99-3; Final Report, 2001.

[8] Choubane B., Page G.C. and Musselman J.A., "Effect of water Saturation Level on Resistance of Compacted Hot-Mix Asphalt Samples to Moisture-Induced Damage", Transportation Research Record 1723. Washington D.C., National Academy Press., 2000.

[9] Mohammad L., Abadie C., Gokmen R. and Puppala A., "Mechanistic Evaluation of Hydrated Lime in Hot-Mix Asphalt Mixtures", Transportation Research Record 1723, Washington D.C., National Academy Press, 2000.

[10] Larry Santucci, "Moisture Sensitivity of Asphalt Pavements, Institute of Transportation Studies, Technology Transfer Program, 2004.

[11] Tunnicliff D., "Performance of Antistripping Additives", Journal of the Association of Asphalt Paving Technologists, 1997, Vol. 66, pp. 334-378.

[12] Ramzi Taha "Use of Cement Bypass Dust as Filler in Asphalt Concrete Mixtures" Journal of Materials in Civil Engineering, July/August 2002, Vol. 14, No. 4, pp. 338-343

[13] Parsons T., "Kiln-Dust-Antistripping Additives for Asphaltic Concrete Mixtures", Technical Report, Newfoundland Department of Works, Services and Transportation, Materials Engineering Division, 1995.

[14] John Emery, "Moisture Damage of Asphalt Pavements and Antistripping Additives", Technical Report, Transportation Association of Canada, Ottawa, September, 1996.

[15] Kamil E. Kaloush, Matthew W. Witczak, "Simple Performance Test for Permanent Deformation of Asphalt Mixtures" Presented at the 81st Annual Transportation Research Board Meeting, Washington D.C., January 2002. 


\section{دراسة تأثير الأضرار الناجمة عن التعرض للمياه على خواص الزحف للخلطات الأسفلتية}

نظرا لأن تجمع المياه على سطح الطرق لا يؤثر فقط على سلامة الحركة

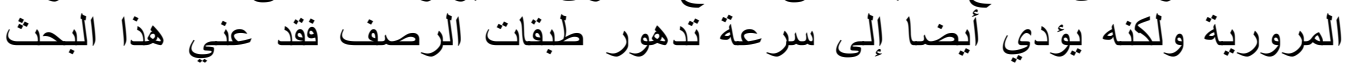

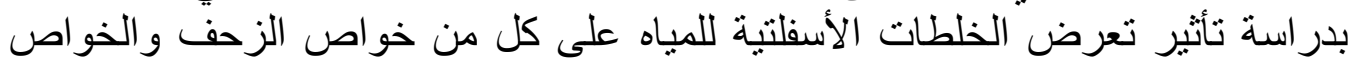

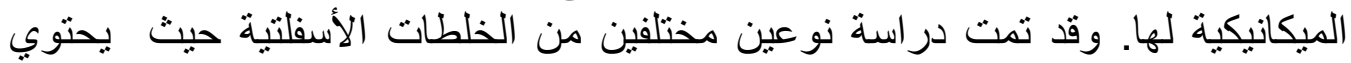

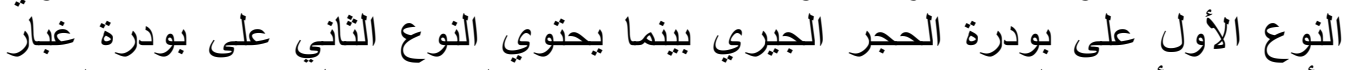

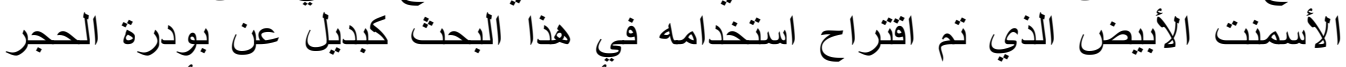

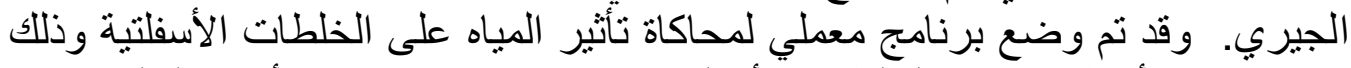

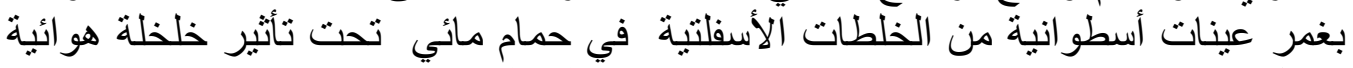

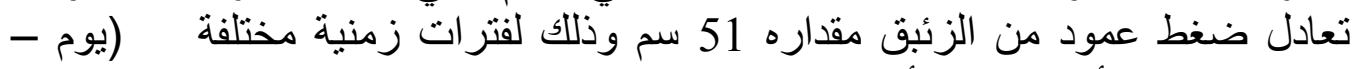

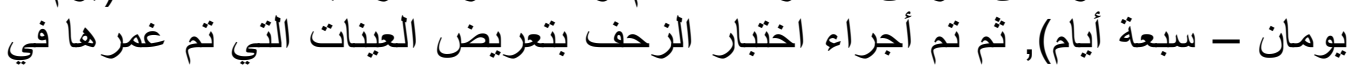

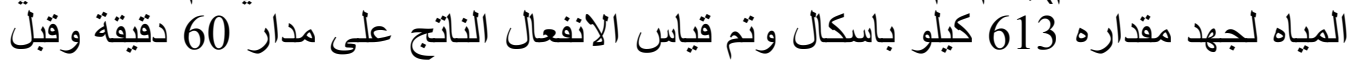

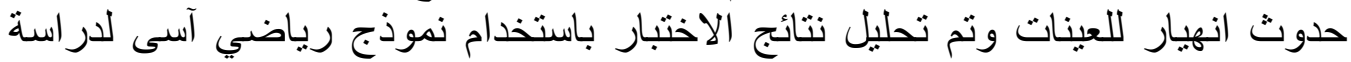

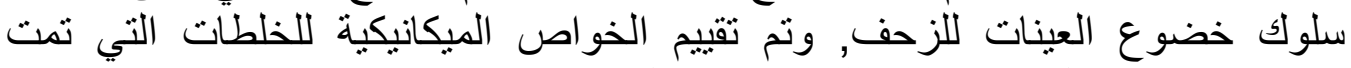

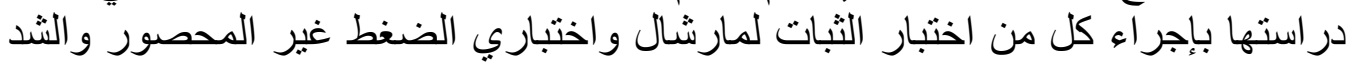

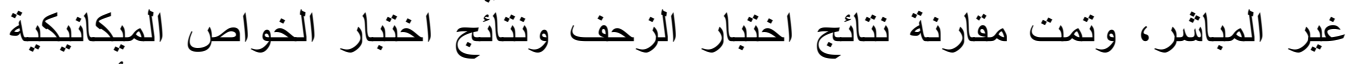

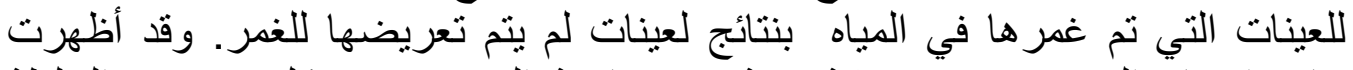

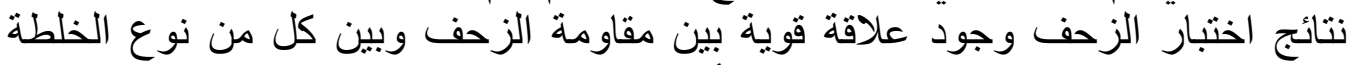

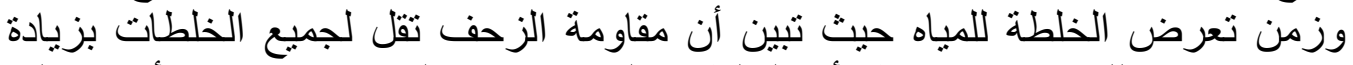

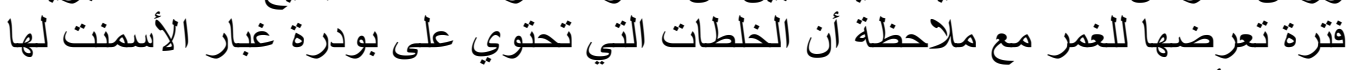

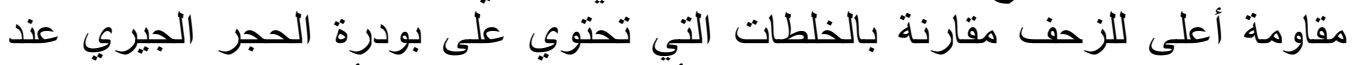

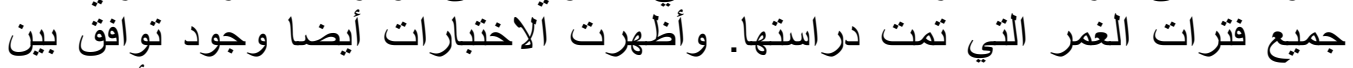

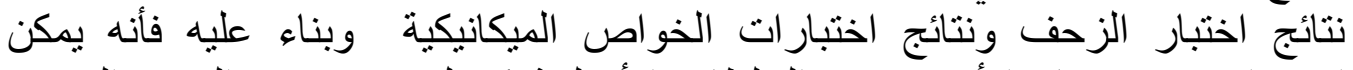

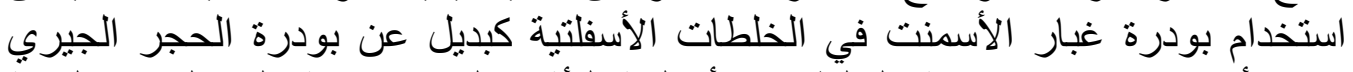

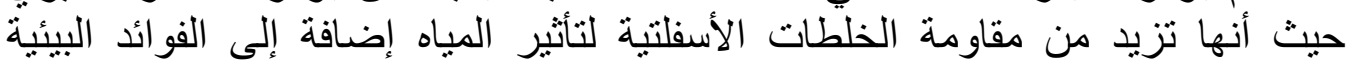
والاقتصادية المرجوة من هذا منا الاستخدام. 